day, to either increase or lessen the dose. If these views are carried out, the danger of scarlet fever will be reduced to a minimum, and those troublesome sequelæ, the dread hitherto of the practitioner, will rarely make their appearance. I am, Sirs, yours, \&c.,

Lirerpool, Sept. 1887. ARTHUR WIGLESWORTH, L.R.C.P.L., \&c.

\section{"THE DURATION OF SCARLET FEVER INFECTIUN."}

To the Editors of THE LANCET.

SIRS,-Your annotation under the above heading in THE LANCET of Oct. 1st calls attention to a subject of great practical importance. The almost universally received opinion is that the infection lasts as long as desquamation continues, and that isolation of the patient is therefore necessary until the completion of that process. No doubt this was the correct and necessary practice in times past, but I question its necessity where the practice of disinfecting the patient's skin is thoroughly carried out. Unquestionably, the desquamating cuticle retains the infection longer than perhaps any other part of the body, but I have for a long time felt that if the skin is thoroughly anointed with carbolised or other disinfecting oil from an early period of the disease, and a daily bath containing some disinfectant be given as soon as. the patient's condition will allow, he may with perfect safety be permitted to mix with others, even while peeling is actively going on. Acting on this belief, I have for some time back been in the habit of shortening the period of isolation without any evil result; and if this practice should, by a more extended experience, prove to be safe, the present congested condition of the hospitals of the Metropolitan Asylums Board might be much relieved.

I am, Sirs, yours faithfully,

Lndlow, 0ct. 1st, 1887: Mark Long, M.D.

\section{J A II B U L I N D I A B E T E S.}

To the Editor's of THE LANCET.

SIRS,-Since the publication of an abstract of my lectures on New Drugs in THe LANCET of Sept. 24th I have had many inquiries relative to my experience of jambul in diabetes. Would you pormit me to answer them briefly in your columns?

First and foremost, the reason why I did not include jambul in my series was, not that I had found it useless, but that I was at the time of lecturing still accumulating results before pronouncing a definite opinion upon the drug. My experience is limited to surgical cases seen at the London and St. Peter's Hospital. They are as follows.

Diabetes insipidus.-No diminution of the urine with jambul.

Diabetes mellitus.-Cases presenting themselves with sloughing ulcers of diabetic origin, or accidental wounds in diabetics, refusing to heal under any application or treatment, gave these results: Water diminished; sugar decreased; ulcers filling in and wounds granulating and healing with surprising rapidity. Dose, $2 \frac{1}{2}$ gr. to $5 \mathrm{gr}$. in perles thrice a day after food.

One case in point may be mentioned. A diabetic of eighteen months' standing, who had been lately under strict diabetic regimen and treatment, applied to me for relief of rapidly increasing sloughy ulcers of leg and thigh. These ulcers caused great pain. The patient stated that he filled a full-sized zinc pail with urine every night, and although he did not measure his urine in the day, he believed it was even greater in quantity. In one week with jambul ( $2 \frac{1}{2}$ gr, thrice daily) the urine diminished to one-half the quantity, and some of the deepest ulcers had filled up and skinned over. Few cases have impressed me so much with the value of jambul in diabetic ulceration as this.

I would seize this opportunity of saying that the New Therapeutical Society will be doing invaluable work if it devote some of its attention to the careful investigation and honest criticism of new drugs and remedies. Systematic and collective experience from the London hospitals alone would suffice in a few weeks to indicate worth, and to detect and reject much of the trash which is to be found in the mass of new remedies at present before the profession. I remain, Sirs, yours truly,

\section{"GAMALIEL IN WHITEHALL."}

To the Editors of THE LANCET.

SIRS,-I have read your article of last week on Mr. SclaterBooth's (I beg Lord Basing's pardon-" the king can do no wrong") invitation to the medical profession to disband themselves and to mistrust one another while trying to combat disease and death. You mention, without comment Lord Basing's sneer at "Gamaliel in Whitehall." May I point out that a Hampshire squire might have read his Scriptures to the extent of learning what Ga maliel's teaching really was: "Let them alone," he says of those expounding truths which were new and possibly inconvenient to himself; "for if this counsel or this work be of men, it will come to nought; but if it be of God, ye cannot overthrow it." This would look like sensible advice-proceeding, indeed, upon the very lines that are commonly followed by the medical profession. It seems also to have come from a mar who knew how to value facts above opinions, not from one whor sought to decry advancing knowledge under cover of a hearsay phrase. I could wish it had been Lord Gamaliel who addressed the Sanitary Institute.

Oct. 3 rd, 1887. I am, Sirs, your obedient servant, WHITEHALL。

\section{HEMIPLEGIA DURING THE PUERPERIUM.}

To the Editors of THE LANCET.

SIRS,-In a conversation to-day with Dr. Finlayson regarding the case of hemiplegia during the puerperium. which is reported in the present issue of THE LANCET, he informed me that two apparently similar cases-that is of puerperal cerebral embolism without cardiac valvular disease-had been reported by himself. I find, on turning to the Obstetrical Journal, vol. vii., p. 666, that this is so, and that $I$ have been wrong in supposing that my case was the first of the kind reported. Apart from the desire to correct this mistake, I am anxious, by referring to these cases of Dr. Finlayson's, to draw the attention of obstetricians further to this affection, which seems more common than is generally supposed; and it would be interesting to know to what extent such cases have occurred in the experience of your readers, or in the experience of others whose records they may have seen. I am, Sirs, yours faithfully,

Newton-terrace, Glasgow, Oct. 1st, $1887 . \quad$ SAMUEL SLOAN.

\section{ACCOMMODATION FOR INFECTIOUS CASES : A SUGGESTION.}

To the Editors of THE LANCET.

SIns, - While there are to-day only eight beds in the fever hospitals available to meet the present epidemic, there are literally hundreds of beds standing empty at the general hospitals - two hundred at Guy's alone. If Guy's, for instance, would contract with the Asylums Board to take the enteric cases, that would relieve about a hundred beds. It would be thought undesirable to admit scarlet fever to special wards in general hospitals, but two of those with beds closed might combine, and, putting all their cases in one hospital, let the other to the Asylums Board. Anything is better than leaving the cases in their own homes, putting the unfortunate children in draughty sheds in November, or sending out the convalescents before they cease to be dangerous.

October 6th, 1887

I am, Sirs, yours \&c.

X. Y. Z.

\section{THE DRAINAGE OF BEXLEY HEATH.}

To the Editors of THE LANCET.

SIRs,-A short time ago I came to this healthily situated place, and was surprised to see how sickly the children and people looked after seeing those at Putney, the place $1 \mathrm{hac}$ been living in. I now attribute it to the want of drainage. Here is a place of several thousand inhabitants using cesspools which drain through the soil into one another: the old garden closets would be perfect safety in comparison. Close to me there is a valley, and in its sides are seen the blackish leakage ultimetely on its way to the Thames. Wells must also receive their share. The main drains of London are not far from us, and yet we will not 
connect. Ought not places of large size be compelled to do so, or use garden closets? It is sad to see lovely Kent villages so polluted, and London children had better be kept there than sent near places of this kind for their bealth. The expense of clearing out cesspools is greater than the rates would be, so that only those who never empty theirs are money gainers by this dirty and dangerous system. Something in your journal might cause people here to make a stir or move the authorities to interfere on behalf of those who wish to breathe real air instead of that from hundreds of impure drain-holes. Will not the cholera, when it comes, seize upon places like this in preference to those where there is drainage or closets in the ground, with no water used? I am, Sirs, yours truly,

G. BLA KELEY, Commander R.N.

Bexley Heath, Kent, Oct. 3rd, 1887.

\section{POOR-LAW MEDICAL OFFICERS' ASSOCIATION.} To the Editors of THE LANCET.

Sins,-1t is proposed at our next Council meeting to take into consideration the Darlington scheme, which, if adopted by the central authority, will enable Boards of Guardians to fix and regulate as they choose the salaries of all their officers. As this is a matter which will seriously affect all Poor-law medical officers, it is absolutely necessary that they should be "up and doing," as no time must be lost, a memorial to the President of the Local Government Board having been sent by the Darlington guardians and a request from them to all Boards of Guardians throughout the country to do the same.

Hoping to receive communications upon the subject from all Poor-law medical officers,

I am, Sirs, yours truly, J. WICKHAM BARNES,

3, Bolt-court, Fleet-street, London, Oct. 5th, 1887.

\section{THE SIXTH INTERNATIONAL CONGRESS OF HYGIENE. \\ (From our Special Correspondent.)}

Vienna, Oct. 2nd.

THE greatest International Congress of Hygiene that has ever been held has now completed its labours. It is somewhat too early to judge the wisdom of its resolutions; and, indeed, these are buried in such a maze of documents, reports, and speeches that no one has yot fully realised what has been done. It is impossible to be in all Sections at one and the same time; and, were this even possible, the confusion of languages often makes it difficult to follow the debates. In this respect the Congress has not been so well managed as its predecessors. In all former congresses French was recognised as the official language. Speeches in other languages were allowed, but on the condition that they were translated into French, and, of course, all resolutions and offlcial documents were drawn up in French, and the votes taken in French. Thus, foreign delegates were kept together and were fully able to follow the proceedings.

Considering the immense preponderance of Austrian delegates and members present, some regulation should have been established on the present occasian to prevent their speaking too often. The Germans, who, as the nearest neighbours, were the next in numbers present, joined heartily with the Austrians in speaking German. Thus speech after speech was pronounced in German, a language which the great majority of the foreign delegates present could not understand. These were so badly translated that the foreigners soon ceased asking for such interpretations; and, in some Sections, no attempt whatsoever was made at translation. Therefore the majority of the foreign members were obliged to pass wearisome hours, without understanding a word of what had been said. The result was that after a little of this experience a great many went away. Vienna is an attractive town; there were many excursions organised, and the proportion of foreign delegates at the Congress became less and less numerous. Instead of sitting out all the meeting, and taking an active part in the debates, they would look in for a moment or two and then revert to the greater attructions of the Ringstrasse. For hours together I was the only Englishman present in the several Sections I attended. Thus the Congress, to a considerable extent, degenerated from an International Congress into an AustroGerman Congress.

Even worse than this was the method of voting. Those present raised their hands for or against the various proposition without any attempt to analyse the vote and ascertain what it represented. Thus, on one occasion, in the First Section, the Baron de Suzor and myself were the only persons present to speak or vote for Russia and England. If we take the Indian Empire, the English colonies, and the Asiatic as well as the European dominions of Russia, it will be found that the interests of something like five hundred million souls only counted as two voices in a division against thirty or forty Viennese doctors, who at most represented one single town. Considering that any Austrian who chose to pay 16s. was admitted as a member of the Congress, it was preposterous to give to hundreds of unknown amateurs who have never studied hygiene the same voting power as the distiuguished representatives of foreign governments and scientific societies. A national local congress could have told us what several hundred Viennese doctors have to say on various sanitary subjects. It was not necessary to bring delegates from all parts of the world to know what opinions prevailed at Vienna. What is wanted is the opinion of various nationalities on subjects of international interest. It would be most useful to record from time to time how this opinion develops itself; but if mere local majorities are to govern the decision of these congresses, there will be no sequence - they will alter according to each place where the congress meets, and will always exhibit contradiction. Thus, in Portugal the immense majority would be in farour of quarantines, and in England the result of the vote would be just the opposite. Evidently it is by nationalities that the vote should be taken. We want to know what nations are in favour of or against quarantines \&c. The Austrians present should have had but one vote (however numerols they might have been), the Germans one vote, and so on for all nations. It is quite easy to call on the representatives of each nation to stand up and give their vote separately, and, when not agreed among themselves, the majority would govern, note being taken whether the vote was unanimous or not. The majority thus obtained would represent the opinion of the Congress-that is to say, a truly international opinion, and not, as at present, an Austrian vote with just a slight sprinkling of foreign elements. The as yet somewhat incomplete list printed sets forth that there were $2414 \mathrm{mem}$ bers of the Congress, and out of this number 1277 are marked as present. Now, of these members present, no less than 397 live in Vienna, and this does not include those who reside in the suburbs of Vienna. Thus, Vienna alone represents something like forty times the voting power of the entire British empire.

These criticisms are all the more necessary and important as it is now decided, in response to an invitation of the British Sanitary Institute and the Association of the Medical Officers of Health, that the next International Congress of Hygiene shall be held in London. As the Universal Exhibition will draw most persons to Paris in 1889, it would be difficult to hold a Congress elsewhere that year; but, on the other hand, Paris has already been the seat of one Congressnamely, the Second International Congress of Hygiene. Consequently there will be a French Congress held in Paris in 1889 , at which foreign representatives will not be obliged to attend, but where they will no doubt be heartily welcome if they choose to go. The Seventh International Congress of Hygiene will then follow in due course two years laterthat is to say, in 1891,--and in London. In the meanwhilo a committee has been elected to organise and prepare the International Congress, consisting of Dr. Brouardel for France, Dr. Dobroslavine for Russia, Dr. Billings for America, Professor F. de Gruber for Austria, Dr. Roth for Germany, Dr. Mosso for Italy, and Professor Corfield and Mr. Shirley Murphy for England. These gentlemen have agreed to meet at Dresden on the 10 th of October next year to talk the matter over, and it is to be hoped that some arrangement will then be made to confer on the next Congress a more truly international and representative character.

In all other respects the present Congress has been a marvellous success. It would be difficult to find in all li urope a town better suited for a Congress than Vienna. The majesty of the buildings, the broad expanse of the thoroughfares, the splendid halls, restaurants, and meeting places all 